\title{
PV System with Reconnection to Improve Output under Non-uniform Illumination
}

\author{
H. Obane, Student Member, IEEE, K. Okajima, Member, IEEE, T. Ozeki, Member, IEEE, \\ and $\mathrm{T}$. Ishii
}

\begin{abstract}
Photovoltaic (PV) systems are often non-uniformly illuminated owing to shadows of neighboring buildings, trees, clouds, etc. In order to reduce the effect of shadows on solar panels, we propose the concept of a PV system with reconnection; this system consists of $P V$ arrays that can be reconnected to minimize the mismatch loss depending on the output of each of its module, measured at regular time intervals. In this study, the relationship between the output improvement with reconnection and the switching interval is shown. For a $3 \mathrm{~kW}$ PV system, under conditions of cloudlessness and cloudiness, a sharp difference in the output improvement relative to the switching interval is not observed. However, under the condition of shading, the output improvement sharply decreases relative to the switching interval; the output improvement at a 1 min switching interval is 0.15 $\mathrm{kWh} \cdot \mathrm{h}(+22.4 \%)$. For the $90 \mathrm{~kW}$ building integrated photovoltaic (BIPV) system, during summer solstice, a sharp difference in the output improvement relative to the switching interval is not observed. However, during the vernal equinox and winter solstice, when a large area of the PV system is shaded for a long period of time, the output improvement sharply decreases relative to the switching interval. The output improvement at a 1 min switching interval is $6.5 \mathrm{kWh} \cdot \mathrm{d}(+2.9 \%)$ during the vernal equinox and 2.3 $\mathrm{kWh} \cdot \mathrm{d}(+3.7 \%)$ during winter solstice.
\end{abstract}

Index Terms-PV, Grid Connected, Building Integration, Mismatch

\section{INTRODUCTION}

$\mathrm{P}$ hotovoltaic (PV) systems have become popular as a new energy source. With an increase in the number of PV systems being installed, there is also an increase in the number of PV systems that are affected by non-uniform illumination owing to shadows of neighboring buildings, trees, clouds, etc. The loss due to partial shading of a PV array is not proportional to the area of the shading; moreover, the array output might be less than the sum of the outputs of all the modules in the array [1]. In general, the loss due to the difference in the module outputs is called a mismatch loss, and it depends on the type of array connection [2]. Further, the modules not contributing to the array output will heat up and might damage the PV system

H. Obane is with University of Tsukuba, Ibaraki, Japan (phone: +81-29-853-5600 (ext.8206); fax: +81-29-853-5134

$\mathrm{K}$. Okajima is with University of Tsukuba, Ibaraki, Japan.

T. Takashi is with National Institute of Advanced Industrial Science and Technology (AIST), Tsukuba, Ibaraki, Japan

T. Ishii is with JX Nippon Oil \& Energy Corporation, Yokohama, Kanagawa, Japan
[3]. Therefore, it is necessary to minimize the decrease in the array output and lower the risk of damage in cases when the PV system might be non-uniformly illuminated.

The AC module technology has been proposed to reduce the effect of problems caused by shading. The AC module converts the direct current to an alternative current at each module, considerably reducing the mismatch loss due to the difference in the module outputs. However, currently, the cost of this module is much higher than that of a conventional system composed of modules and a central inverter. Therefore, in large PV systems such as PV power generation system, the total cost of reducing the mismatch loss will be higher. Furthermore, the additional conversion loss of the system is not avoidable even if a PV system is not shaded [4].

The other technology to reduce mismatch loss is the string inverter with shade-tolerant maximum power point tracking [5]. This technology will minimize mismatch loss as compared to performing MPPT at the array level. However, in the case of almost all modules shaded in a string, this string inverter might not obtain enough energy due to the lower limit of an inverter.

In this study, we suggest a PV system with reconnection [6] [8], where the array connection is reconnected at regular time intervals to minimize the mismatch loss. Thus far, some studies have shown effective array connections by taking into account the effect of shading, to minimize the mismatch loss [9] - [11]. However, these studies assumed fixed PV array connections for the installed PV systems without optimizing the connections. Some studies have also shown a reconnection process based on the assumption that the array connections change in real-time [12] - [15]. In particular, Nguyen et al. [14] and Patnaik et al. [15] have reported an improvement in the performance of PV systems with reconnection. However, these studies have not shown the effects of reconnection or evaluated the daily output power. We have hitherto reported the effect of reconnection for cases where a building integrated photovoltaic (BIPV) system would be in the shadow of a neighboring building [16]. The simulation assumed a 1 min switching interval. However, taking into account mechanical factors such as loss by switching or system reliability, longer time intervals are sometimes required.

Therefore, in this study, we aim to study the relationship between the output improvement with reconnection and the switching interval. The output energy of two PV systems was evaluated by considering different switching intervals, as a case study. 


\section{PV System WITH RECONNECTION}

In this study, a PV system with reconnection is proposed to minimize the mismatch loss. This PV system measures the output characteristics of its module, such as output current or voltage, and switches connections according to the module output. Furthermore, the PV system can also be used to detect module or their devise failure in detail by measuring the output characteristics of each module. However, in some PV systems such as a BIPV system, it might be difficult to detect module failure and avoid large system loss. A PV system with reconnection can be beneficial in this case. Up to now, we have been studying the devise of this PV system for measuring or switching [7]. In order to study the potential of this system for minimizing the mismatch loss, reconnections were assumed to change according to the output characteristics of the modules.

One of the processes involved in reconnection is the optimization of array connections by calculating the output of several connection patterns. The array connection with the largest output is selected as the optimized connection. However, the number of possible array connections may be extremely large. Therefore, the calculated array connections are adjusted in advance according to the following two requirements:

- The voltage of the array connection should satisfy the input voltage of an inverter.

- The shaded and unshaded modules should be connected in a sequence, because the resistance of a shaded module may result in a decrease in the output.

Shaded and unshaded modules are differentiated by K-means clustering [17] with respect to the short-circuit current of each module. The array output is then calculated using the equivalent circuit of a solar cell [18] and by applying Kirchhoff's second law to the array connections.

\section{ANALYSIS OF A 3-KW FIELD PV SYSTEM}

In order to study the relationship between the output improvement with reconnection and the switching interval, the output energy of $3 \mathrm{~kW}$ field PV systems was evaluated considering various switching intervals. The evaluation is based on the experimental data of real-time short-circuit currents of each module under conditions of cloudlessness, cloudiness, and shading.

\section{A. 3-kW Field PV System}

This system has a total capacity of $3 \mathrm{~kW}$ and each array consists of 20 modules (SHARP ND 150-AN) that include 3 bypass diodes per 14 cells. The installation is located at the National Institute of Advanced Industrial Science and Technology (AIST) $\left(36^{\circ} 03^{\prime} \mathrm{N}, 140^{\circ} 08^{\prime} \mathrm{E}\right)$ in Japan. 10 modules are connected in series as an array, as shown in Fig. 1. The module specifications are listed in Table I. The PV system is oriented south $\left(180.0^{\circ}\right)$ and is located in the shadows of trees. The operation point of the power conditioner is determined to be the peak power between $150 \mathrm{~V}$ and $500 \mathrm{~V}$, using the hill-climbing method.
TABLE I

SPECIFICATIONS OF THE PV MODULE OF THE 3-KW PV SYSTEM

\begin{tabular}{ll}
\hline \hline maximum power $\left(P_{\max }\right)$ & $150 \mathrm{~W}$ \\
open-circuit voltage $\left(V_{\mathrm{oc}}\right)$ & $25.4 \mathrm{~V}$ \\
short-circuit current $\left(I_{\mathrm{sc}}\right)$ & $8.09 \mathrm{~A}$ \\
operating voltage at maximum power $\left(V_{\max }\right)$ & $20.5 \mathrm{~V}$ \\
operating current at maximum power $\left(I_{\max }\right)$ & $7.32 \mathrm{~A}$ \\
$\left(\right.$ AM $\left.1.5,1000 \mathrm{~W} / \mathrm{m}^{2}, 25^{\circ} \mathrm{C}\right)$ & \\
\hline
\end{tabular}

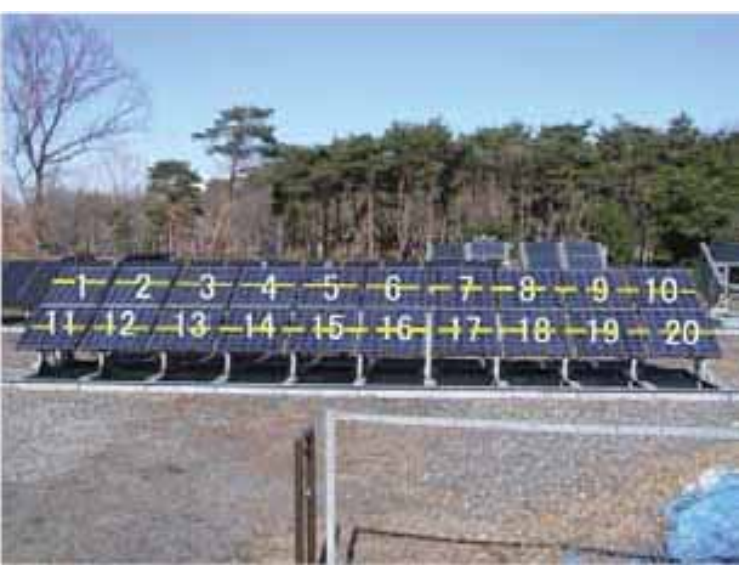

Fig. 1. Experimental PV array.

\section{B. Real-time short-circuit currents}

The short-circuit currents of each module are measured in real-time using a clamp meter (KYORITSU AC/DC Clamp Adaptor, Model 8113). Ambient temperature (thermocouple) and direct irradiance on module 5 (EKO ML-020VM) are also acquired simultaneously. Fig. 2 shows the non-uniform short-circuit currents measured for $1 \mathrm{~h}$ under conditions of cloudlessness, cloudiness, and shading. The plotting interval was $1 \mathrm{~s}$. Under the condition of cloudlessness, sharp changes in short-circuit currents were not observed during the $1 \mathrm{~h}$; however, the short-circuit currents sometimes decreased owing to the presence of clouds. The average standard deviation of the short-circuit currents during $1 \mathrm{~h}$ was $0.09 \mathrm{~A}$. The non-uniformity in the short-circuit currents can be attributed to inconsistent module performances. Under the condition of cloudiness, the short-circuit currents occasionally changed sharply as the direct irradiance decreased owing to the presence of clouds. The average standard deviation was $0.11 \mathrm{~A}$, which is 0.02 A higher than that under the condition of cloudlessness. As the clouds moved, the standard deviation of the short-circuit current reached a maximum value of 0.84 A. Under shading, two modules were gradually shaded together. The average standard deviation was $0.81 \mathrm{~A}$ and reached a maximum value of $1.4 \mathrm{~A}$. 


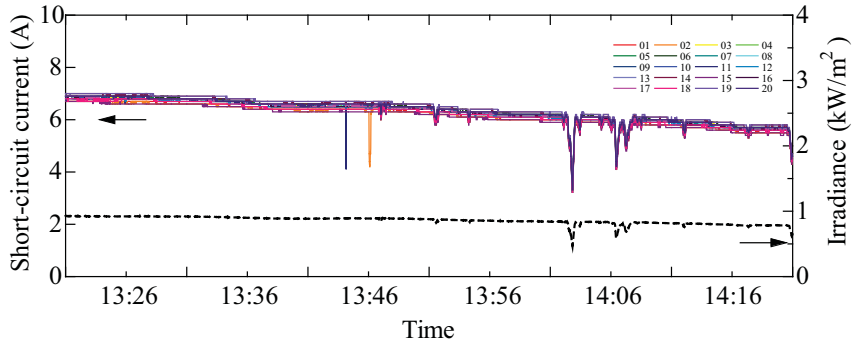

(A) Cloudlessness(14/09/09)

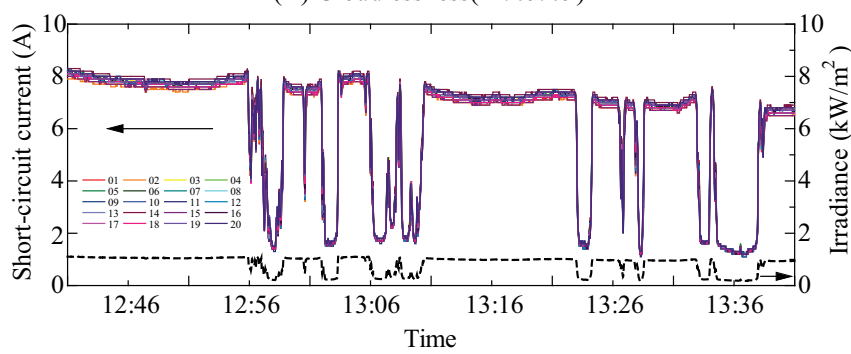

(B) Cloudiness $(24 / 09 / 09)$

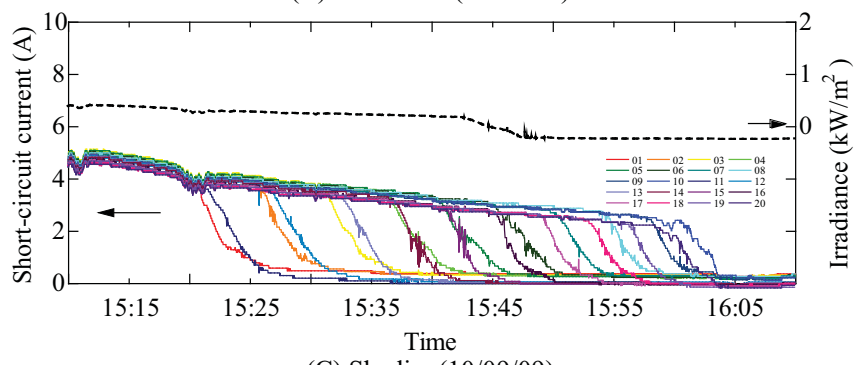

(C) Shading(10/09/09)

Fig. 2. Short-circuit current of each module under cloudlessness, cloudiness, and shading $(\mathrm{A})-(\mathrm{C})$

\section{Hourly output improvement by reconnection, considering} different switching intervals

On the basis of the experimental data, the output energy of the system with reconnection is calculated using an equivalent circuit of a solar cell and by applying Kirchhoff's second law according to the optimized array connections. Table II lists the hourly output energy obtained for different time intervals $(\mathrm{kWh} \cdot \mathrm{h})$. The parenthetic values show the percentage of increase in output when compared with the output of a system with fixed array connection. The output of the system with fixed array connection was $1.93 \mathrm{kWh} \cdot \mathrm{h}$ (cloudlessness), $1.77 \mathrm{kWh} \cdot \mathrm{h}$ (cloudiness), and $0.61 \mathrm{kWh} \cdot \mathrm{h}$ (shading). Fig. 3 shows the hourly output improvement with reconnection, considering different switching intervals. Under conditions of cloudlessness and cloudiness, a sharp difference in the output improvement relative to the switching interval is not observed. Hence, even at a switching interval of 60 mins, sufficient output improvement is expected when compared with the improvement at a short switching interval. The output improvement at a $60 \mathrm{~min}$ switching interval is $0.03 \mathrm{kWh} \cdot \mathrm{h}(+1.6 \%)$ and $0.04 \mathrm{kWh} \cdot \mathrm{h}$ $(+1.8 \%)$ under conditions of cloudlessness and cloudiness, respectively. On the other hand, under the condition of shading, the output improvement sharply decreases relative to the switching interval. Lower output occurs than that of fixed array connection at a long switching interval because large mismatch loss is caused until subsequent reconnecting. At a $1 \mathrm{~s}$ switching interval, an output improvement of $0.17 \mathrm{kWh} \cdot \mathrm{h}(+26.7 \%)$ is achieved. However, switching array connections at intervals of $1 \mathrm{~s}$ might be difficult owing to mechanical constraints. A comparison between the output improvements at a 1 min interval and 5 min interval reveals that the difference in the output improvements between the two is $0.10 \mathrm{kWh} \cdot \mathrm{h}$. Fig. 4 shows the output curves at $1 \mathrm{~min}$ and $5 \mathrm{~min}$ intervals under the condition of shading. For a 5 min switching interval, the output occasionally decreases sharply. Hence, switching intervals of over 5 min would not be effective. However, the difference between the output improvements at a switching interval of 1 $\min$ and $1 \mathrm{~s}$ is only $0.2 \mathrm{kWh} \cdot \mathrm{h}$. Therefore, in light of the mechanical constraints stated earlier, a 1 min switching interval would be effective. In this case, an output improvement of 0.15 $\mathrm{kWh} \cdot \mathrm{h}(+22.4 \%)$ is achieved.

TABLE II

HOURLY OUTPUT ENERGY ACCORDING TO DIFFERENT TIME INTERVAL $(\mathrm{KWH} \cdot \mathrm{H})$

\begin{tabular}{llll}
\hline \hline & Cloudlessness & Cloudiness & Shading \\
\hline \hline Fixed & 1.93 & 1.77 & 0.61 \\
1 s interval & 1.97 & 1.81 & 0.78 \\
& $(+1.9 \%)$ & $(+1.8 \%)$ & $(+26.7 \%)$ \\
1 min interval & 1.97 & 1.81 & 0.76 \\
& $(+1.8 \%)$ & $(+1.8 \%)$ & $(+22.4 \%)$ \\
5 min interval & 1.97 & 1.80 & 0.66 \\
& $(+1.8 \%)$ & $(+1.7 \%)$ & $(+6.7 \%)$ \\
60 min interval & 1.96 & 1.81 & 0.53 \\
& $(+1.6 \%)$ & $(+1.8 \%)$ & $(-13.5 \%)$ \\
\hline \hline
\end{tabular}

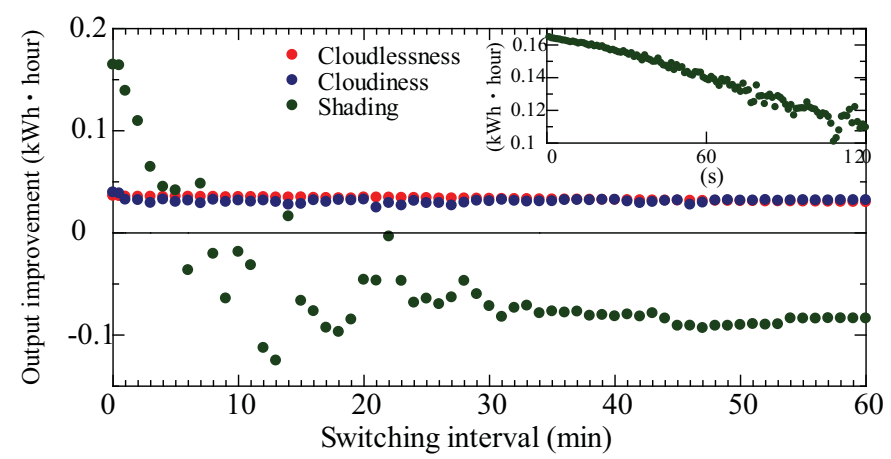

Fig. 3. Hourly output improvement with reconnection according to switching interval $(\mathrm{kWh} \cdot \mathrm{h})$.

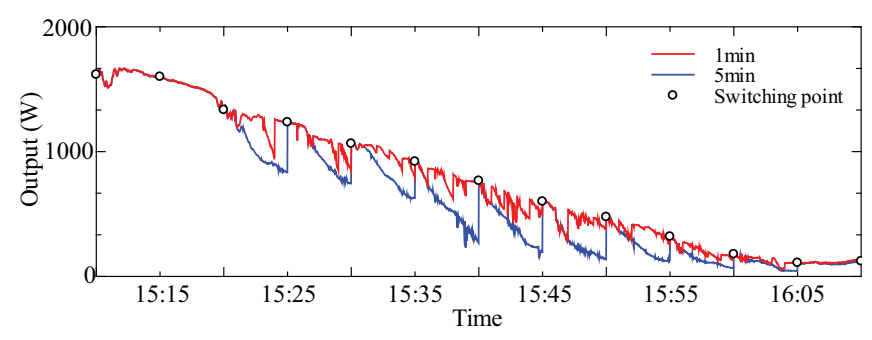

Fig. 4. Output curves obtained for switching intervals under the condition of shading.

\section{ANALYSIS IN 10-KW BIPV SYSTEM}

In order to study the relationship between the output improvement by reconnection and switching interval in another 
system, the output energy of $10 \mathrm{~kW}$ BIPV systems was also evaluated. The evaluation was performed by carrying out simulations on the systems under the conditions of shading during the vernal equinox, summer solstice, and winter solstice. The plotting interval of the shadow in the simulation was $1 \mathrm{~min}$.

\section{A. BIPV System}

The BIPV system is installed vertically on the facade of a building. The BIPV facade is oriented southeast $\left(122.34^{\circ}\right)$ at a height of $150.0 \mathrm{~m}$ and is located in the shadow of the other building; this orientation is similar to the actual location of two buildings in Yokohama, as shown in Fig. 5. The system has a total capacity of $90 \mathrm{~kW}$ and comprises seven arrays with a total of 504 modules. Each array consists of 72 modules, and a 10 $\mathrm{kW}$ inverter is composed of 72 modules. The operation point of the power conditioner is determined to be the peak power between $200 \mathrm{~V}$ and $500 \mathrm{~V}$. The module specifications are listed in Table III. As seen in Fig. 6, each module is connected longitudinally to minimize the mismatch loss occurring as a result of shadows on the left and right parts of the array; these shadows are found to appear most often. However, even if each module is connected longitudinally, the mismatch loss will occur under particular shadow patterns. Shadows on the corners of the array or on the upper and lower part of the array often cause large amounts of mismatch loss.

The BIPV system is placed in the shadow of the other building. Fig. 7 shows the shadow profile on the BIPV facade. During vernal equinox, the shaded region is significantly large between 8:58 AM and 1:04 PM. During the summer solstice, the shadow only lasts for approximately $49 \mathrm{~min}$; thus, its effect on the system output is small. During the winter solstice, all modules are in the shade before 10:29 AM and are completely exposed by 11:54 AM.

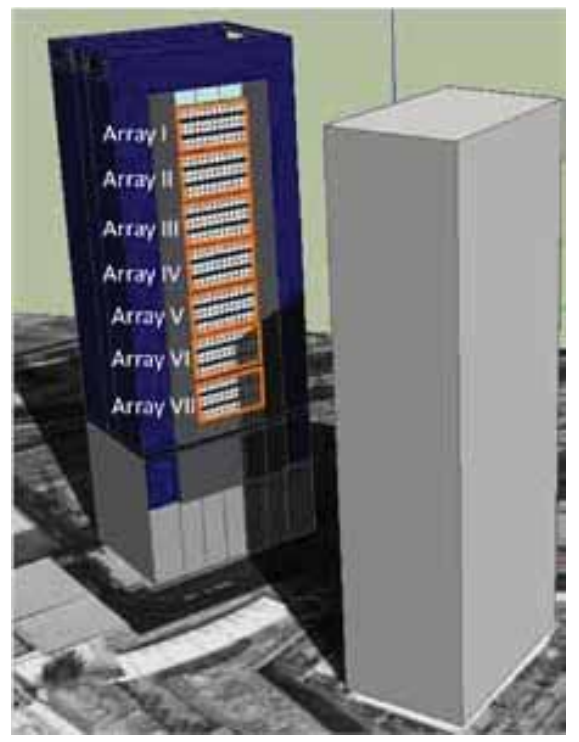

Fig. 5. Schematic diagram of PV arrays under shadow.

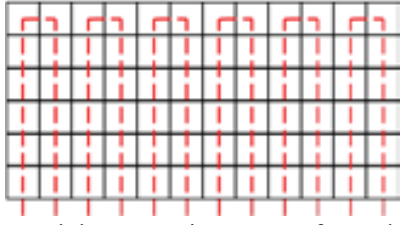

Fig. 6. Module connection pattern for each array.

TABLE III

SPECIFICATIONS OF PV MODULE FOR BIPV SYSTEM

\begin{tabular}{ll}
\hline \hline maximum power $\left(P_{\max }\right)$ & $168 \mathrm{~W}$ \\
open-circuit voltage $\left(V_{\mathrm{oc}}\right)$ & $30.2 \mathrm{~V}$ \\
short-circuit current $\left(I_{\mathrm{sc}}\right)$ & $7.5 \mathrm{~A}$ \\
operating voltage at maximum power $\left(V_{\max }\right)$ & $24.0 \mathrm{~V}$ \\
operating current at maximum power $\left(I_{\max }\right)$ & $6.8 \mathrm{~A}$ \\
\hline \hline
\end{tabular}

operating current at maximum power $\left(I_{\max }\right)$

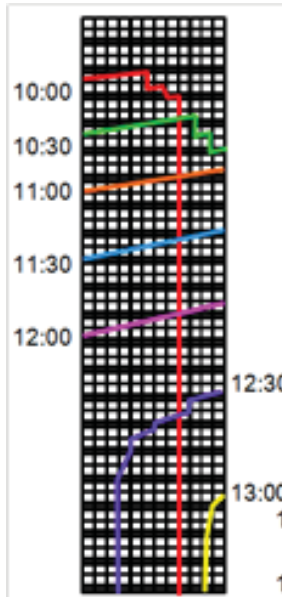

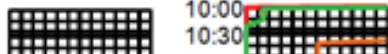

ifmen

+2:-2:

a+men

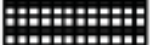

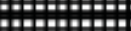

+世曲曲

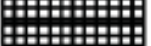

ifm+口

inan

m+2

(2.+.".

H+27+m

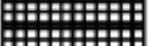

\#\#曲曲

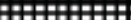

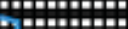

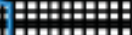

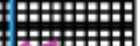

Vernal equinox

Summer solstice

Fig. 7. Shadow profile on BIPV facade.

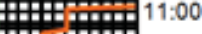

覀事 $11: 30$

He⿻肀二丿

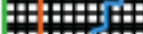

舟事的

H.7.

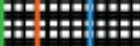

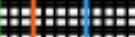

Hy+m

Hiffy

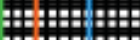

HefH

H舟刍

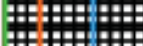

事事

H.7.8.

平册册

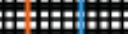

Winter solstice

\section{B. Solar Irradiance}

The solar irradiance on the unshaded solar modules, $I_{\text {unsd }}$, is calculated as the sum of the direct irradiance on the tilted surfaces, $I_{\mathrm{T}, \mathrm{d}}$; diffuse irradiance, $I_{\mathrm{T}, \mathrm{b}}$; and irradiance for reflection, $I_{\mathrm{T}, \mathrm{r}}$, as follows:

$I_{\text {unsd }}=I_{T, b}+I_{T, d}+I_{T, r}$

In the calculation, the Erbs and Perez models were used to distinguish between the direct and the diffuse irradiances [19], [20]. A module in the shade is assigned a direct irradiance of zero. Fig. 8 shows the solar irradiation calculated for shaded and unshaded modules during the vernal equinox, summer solstice, and winter solstice. In the calculation, the scattering ratio was determined to be 0.2 and the ratio of daily clearness was determined to be 0.75 on a sunny day. The irradiance on the unshaded module peaked at around 9:00 AM and decreased gradually thereafter. After 1:00 PM, the irradiance was less than $200 \mathrm{~W} / \mathrm{m}^{2}$; hence, the solar cell did not generate considerable power. During the vernal equinox and summer solstice, the irradiance on the shaded module was sometimes greater than $100 \mathrm{~W} / \mathrm{m}^{2}$; hence, the shaded module could generate some amount of power, even under the condition of shading. However, during the winter solstice the irradiances were too low for the shaded module to generate sufficient power. 


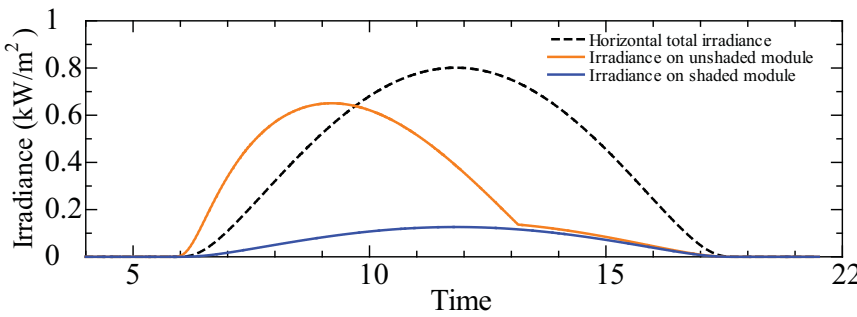

(A) Vernal equinox

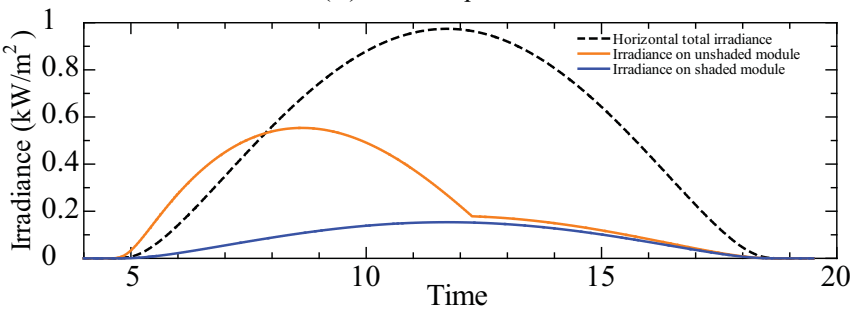

(B) Summer solstice

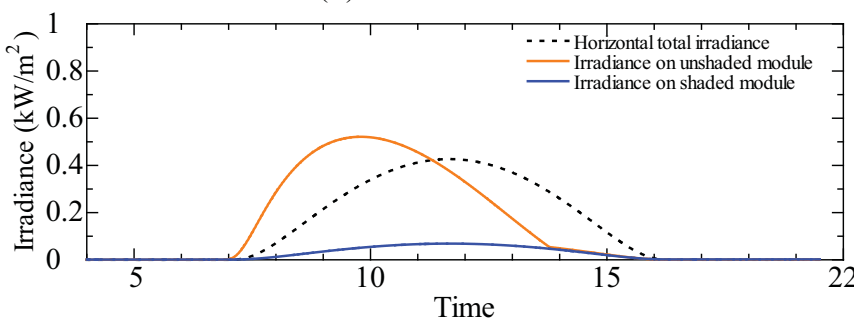

(C) Winter solstice

Fig.8. Solar irradiance on solar panels (Scattering ratio: 0.2) (A) - (C).

\section{Output improvement with reconnection, considering different switching intervals}

The system output is given by the sum of the outputs of the seven arrays. The cell temperature $T$ used to calculate module output is determined using the Sandia national laboratories (SNL) model [21], based on real metrological data. Table IV lists the daily output energies for the PV system with reconnection and for the conventional system with fixed array connections. The parenthetic values show the percentage of increase in output when compared with the output of a system with fixed array connection The outputs with fixed array connections are $190.8 \mathrm{kWh} \cdot \mathrm{d}$ (vernal equinox), $290.1 \mathrm{kWh} \cdot \mathrm{d}$ (summer solstice), and $45.9 \mathrm{kWh} \cdot \mathrm{d}$ (winter solstice). Fig. 9 shows the daily output improvement with reconnection considering different switching intervals. During the summer solstice, a sharp difference in the output improvement is not observed. Even at a switching interval of $1 \mathrm{~min}$, an output improvement of only $1.3 \mathrm{kWh} \cdot \mathrm{d}(+0.2 \%)$ is observed. This is because a small area of the PV system is shaded for a short period of time during summer solstice. Thus, reconnection for this short period of time might not be needed under light shading conditions. During the vernal equinox and winter solstice, the output improvement sharply decreases relative to the switching interval. In particular, at a switching interval of over 10 mins, the output of the PV system with reconnection might be less than that of the PV system with fixed array connections. A comparison between the output improvements at a $1 \mathrm{~min}$ interval and a $5 \mathrm{~min}$ interval reveals that the difference in the output improvement between the two is large This difference is
$3.6 \mathrm{kWh} \cdot \mathrm{d}$ during the vernal equinox and $1.1 \mathrm{kWh} \cdot \mathrm{d}$ during the winter solstice. Thus, under heavy shading conditions, a large area of the PV system is shaded for long period of time. In this condition, a 1 min switching interval would be effective. For the 1 min switching interval, an output improvement of $5.5 \mathrm{kWh} \cdot \mathrm{d}$ $(+2.9 \%)$ and $1.3 \mathrm{kWh} \cdot \mathrm{d}(+3.7 \%)$ is observed during the vernal equinox and winter solstice, respectively. Fig. 10 shows output curves obtained for different time intervals under the condition of shading. For the $5 \mathrm{~min}$ switching interval, the output occasionally changes sharply.

TABLE IV

DAILY OUTPUT ENERGY ACCORDING TO SWITCHING INTERVAL (KWH·D)

\begin{tabular}{llll}
\hline \hline & Vernal equinox & Summer solstice & Winter solstice \\
\hline \hline Fixed & 190.8 & 290.1 & 45.9 \\
Reconnection & 196.3 & 291.4 & 47.6 \\
$(1$ min interval $)$ & $(+2.9 \%)$ & $(+0.2 \%)$ & $(+3.7 \%)$ \\
Reconnection & 193.9 & 291.1 & 46.5 \\
$(5$ min interval $)$ & $(+1.6 \%)$ & $(+0.1 \%)$ & $(+1.4 \%)$ \\
Reconnection & 178.4 & 290.1 & 36.9 \\
$(60$ min interval $)$ & $(-6.5 \%)$ & $(+0.0 \%)$ & $(-19.6 \%)$ \\
\hline \hline
\end{tabular}

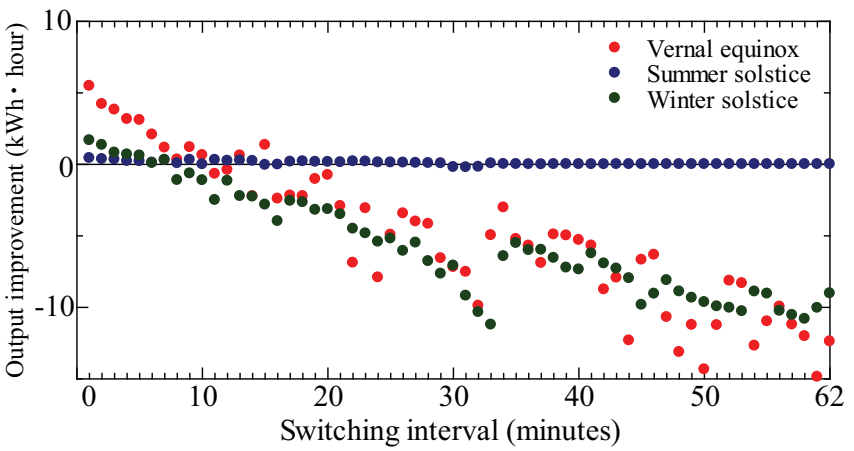

Fig. 9. Daily output improvement by reconnection considering different switching intervals $(\mathrm{kWh} \cdot$ day)

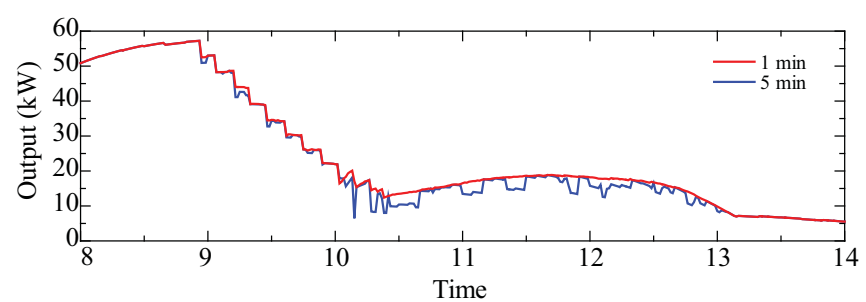

(A) Vernal equinox

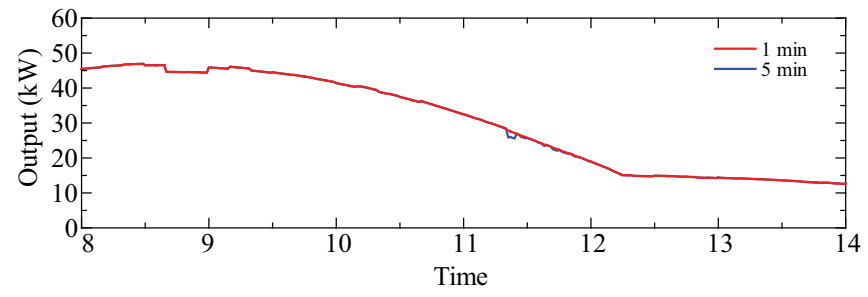

(B) Summer solstice 


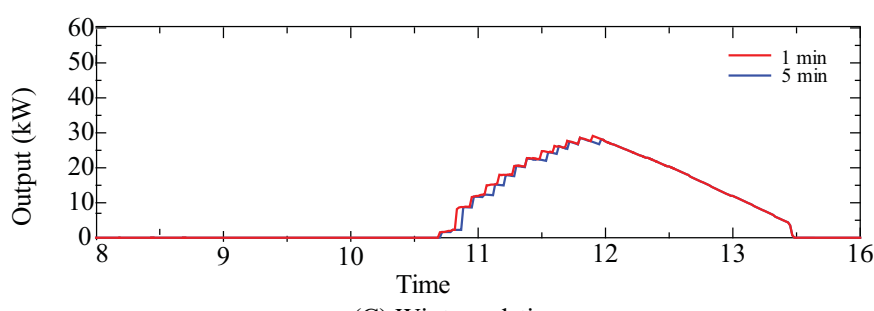

(C) Winter solstice

Fig. 10. Output curves obtained for different switching intervals under the condition of shading $(\mathrm{A})-(\mathrm{C})$.

\section{CONCLUSION}

In this study, a PV system with reconnection is proposed to minimize the mismatch loss. Using this technique, mismatch loss can be reduced even in the case of almost all module shaded in a string where a string inverter might not obtain enough energy. We have evaluated the relationship between the output improvement with reconnection and the switching interval. The output energy of two PV systems was evaluated considering different switching intervals, as a case study.

The output energy of the $3 \mathrm{~kW}$ PV system with reconnection was calculated on the basis of the experimental data of real-time short-circuit currents of each module under conditions of cloudlessness, cloudiness, and shading. Under the condition of shading, the output improvement sharply decreased relative to the switching interval. The output improvement at a $1 \mathrm{~min}$ switching interval was $0.15 \mathrm{kWh} \cdot \mathrm{h}(+22.4 \%)$.

In the case of the $90 \mathrm{~kW}$ BIPV system that is installed vertically on the facade of a building, the output energy with reconnection was evaluated during the vernal equinox, summer solstice, and winter solstice. The BIPV system was placed in the shadow of the other building. During the vernal equinox and winter solstice, when large area of the PV system was shaded for a long term, the output improvement sharply decreased relative to the switching interval. The output improvement at the $1 \mathrm{~min}$ switching interval was $6.5 \mathrm{kWh} \cdot$ day $(+2.9 \%)$ during the vernal equinox and $2.3 \mathrm{kWh} \cdot$ day $(+3.7 \%)$ during the winter solstice. Thus, under heavy shading conditions, a short switching interval would be effective. On the other hand, under light shading conditions, a longer switching interval would provide sufficient output improvement. The methodology is almost the same as the other Si base module. Thus, we consider the relationship between the output improvement with reconnection and the switching interval is also seen for the other Si based module.

\section{REFERENCES}

[1] Ward T. Jewell, Timothe D. Unruh "Limits on cloud-induced fluctuation in photovoltaic genaration" , IEEE Transactions on Energy Conversion, Vol.5, No.1, pp.8 -14, 1990.

[2] Kovach, A,M, "Effect of partial shading on the energy performance of photovoltaic arrays integrated onto buildings. VDI-Verlag, Dusseldorf, 1995.

[3] M. S. Swaleh, M. A. Green, "Effect of shunt resistance and bypass diode on the shadow tolerance of solar cell modules," Solar cells, Vol.5, No.2, pp183-198, 1982.

[4] Enphase Microinverter M190, Datasheet, 142-00005 REV 05.

[5] Dr. Andrew Swingler, "Photovoltaic String Inverters and Shade-Tolerant Maximum Power Point Tracking: Toward Optimal Harvest Efficiency and Maximum ROI", Schneider Electric, White Paper, 2010.
Available: http:/www2.schneider-electric.com/documents/support/ white-papers/seshadetolerantwp.pdf

[6] T. Yamada, K. Otani, K. Kato, T. Takashima, K. Sakura, T. Yamaguchi, "New methodology for optimum PV system design by considering dynamic I-V characteristics - analytical study - “, PVSEC-14 Bangkok, Thailand, 2004.

[7] T. Oozeki, T. Yamada, K. Kato, T. Doi, H. Obane, K. Okajima, "Study on an automatic optimization of Photovoltaic system output energy -Concept of Smart PV", proceedings of JSES/JWEA Joint Conference pp141-144, 2009 (In Japanese).

[8] H. Obane, T. Oozeki, Takao Yamada, K. KATO, T. Doi, K. Okajima, "Study on minimizing mismatch loss using optimization of photovoltaic system”, Annual Meeting Record I.E.E. Japan, 2010 (In Japanese).

[9] D.Picault, B.Taison, S.Bacha, J.de la Casa, J. Aguilera, "Forecasting photovoltaic array power connection subject to mismatch loss" Solar Energy, Volume 84, Issue 7, pp 1301 - pp1309, 2010.

[10] N.D. Kaushikaa, Anil K. Rai, “An investigation of mismatch loss in solar photovoltaic cell networks” ,Energy, 32, pp755-759, 2007.

[11] Zilles R, Lorenzo E. "An Analitical model for mismatch losses in PV arrays” , International Journal of Solar Energy, pp113-pp118, 1993.

[12] Chin Chang "Solar cell array having lattice or matrix structure and method of arranging solar cells and panels, "Patent No; US 6,635,817 B2. 2003.

[13] Read A. Sherif, Karim S. Boutros, Moorpark United States Patent, "Solar module array with reconfigurable tile" , Patent No; US 6,635,944 B1. 2002.

[14] D. Nguyen, B. Lehman, "An adaptive solar photovoltaic array using model-based reconfiguration algorithm", IEEE transactions on industrial electronics, 55, NO. 7, pp2644- 2654, 2008.

[15] B. Patnaik, P. Sharma, E. Trimurthulu, S. P. Duttagupta, V. Agarwal, "Reconfiguration strategy for optimization of solar photovoltaic array under non-uniform illumination conditions", $37^{\text {th }}$ IEEE PVSC, Washington, Seattle, July $19-24,2011$.

[16] H. Obane, K. Okajima, T. Ozeki, T. Yamada, T. Ishii, "Minimizing mismatch loss in BIPV system by reconnection", $37^{\text {th }}$ IEEE PVSC, Washington, Seattle, July 19 -24, 2011.

[17] M. David, "Chapter 20. An Example in Inference Task: Clustering", Information theory, inference and learning algorithms. cambridge university press. pp. $284-292,2003$.

[18] T. Yamada, K. Otani, K. Kato, T. Takashima, K. Sakura, T. Yamaguchi, "Experimental study on new methodology for optimum PV system design by considering dynamic I-V characteristics", PVSEC-14, Bangkok, Thailand, 2004.

[19] Erbs, D.G., S.A.Klein, J.A.Duffie, "Estimation of the diffuse radiation fraction for hourly, daily and monthly average global radiation", Solar Energy, 28, No.4, pp.293-302, 1982.

[20] Perez, R., R.Seals, P.Ineichen, R.Estimation and R.Stewart, "Modeling daylight availability and irradiance model for tilted surfaces", Solar Energy, 44, No.5, pp.271-289, 1990.

[21] King DL, Boyson WE, Kratichvil JA, "Photovoltaic performance model", SAND2004-3535. pp15 - 19, 2004

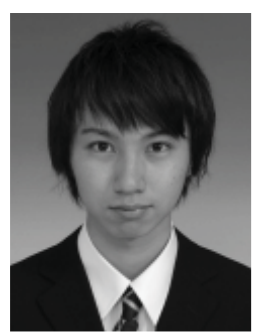

Hideaki Obane (Student Member, IEEE) was born in Shizuoka, Japan on Oct 29, 1987. He received a Bachelor's degree in engineering systems from the University of Tsukuba, Tsukuba, Ibaraki, Japan, in 2010. $\mathrm{He}$ is now a graduate student at the Department of Risk Engineering, Graduate School of Systems and Information Engineering, University of Tsukuba, Tsukuba, Ibaraki, Japan. His research interests include solar cell technology and risk engineering. 

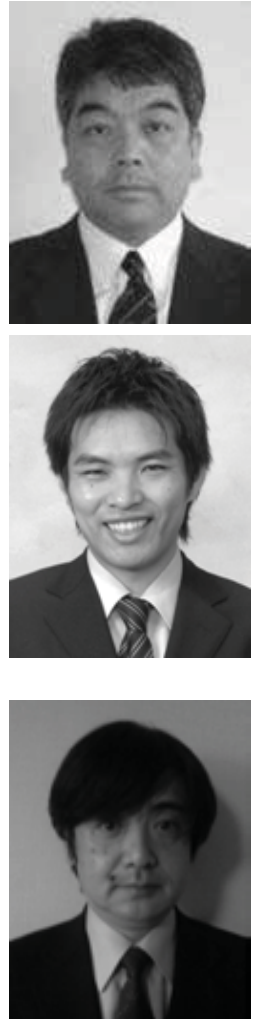

Keiichi Okajima (Member, IEEE) was born in Iwate, Japan on May14, 1968. He received a Ph D. degree in chemical engineering from The University of Tokyo in 1999. During 1998-2005, he was a research associate at Shizuoka University. $\mathrm{He}$ is presently a lecturer at University of Tsukuba. He has studied on analysis of energy systems. Japan Solar Energy Society, Japan Society of Energy and Resources, Society of Chemical Engineers Japan, Institute of Life Cycle Assessment Japan member.

Takashi Oozeki (Member, IEEE) received the B.S. degree in electrical engineering from Nagoya institute of technology, Nagoya, Japan, in 2000,and Master and Ph.D. degree in engineering from the Tokyo University of Agriculture and Technology, Tokyo, Japan, in 2002 and 2005, receptivity. He has been National Institute of Advanced Industrial Science and Technology, Ibaraki, Japan since 2005. His research interests include photovoltaic system's technologies, grid connection of the distributed generator, and solar energy.

Takafumi Ishii received the B.D. and M.D. in chemistry from University of Tokyo, Tokyo, Japan in 1982 and 1984 respectively. He is a principal specialist of JX Nippon Oil \& Energy Co.Yokohama, Japan, and had been working since 1984 for petroleum refinery, since 1985 on $R \& D$ of organic synthesis and polymer science, and since 2003 on R\&D of energy systems. His latest work is the development and demonstration of photovoltaic systems. His research interests include the methods of maximizing photovoltaic system yield, the methods of detecting system faults, and the combination systems with other energy devices than photovoltaics. 